\title{
Quality of colonoscopy in an organised colorectal cancer screening programme with immunochemical faecal occult blood test: the EQulPE study (Evaluating Quality Indicators of the Performance of Endoscopy)
}

\author{
Manuel Zorzi, ${ }^{1}$ Carlo Senore, ${ }^{2}$ Filippo Da Re, ${ }^{3}$ Alessandra Barca, ${ }^{4}$ Luigina Ada Bonelli, ${ }^{5}$ \\ Renato Cannizzaro, ${ }^{6}$ Renato Fasoli, ${ }^{7}$ Lucia Di Furia, ${ }^{8}$ Emilio Di Giulio, ${ }^{9}$ \\ Paola Mantellini, ${ }^{10}$ Carlo Naldoni, ${ }^{11}$ Romano Sassatelli, ${ }^{12}$ Douglas Rex, ${ }^{13}$ \\ Cesare Hassan, ${ }^{14}$ Marco Zappa, $^{15}$ the Equipe Working Group
}

For numbered affiliations see end of article.

\section{Correspondence to}

Dr Manuel Zorzi,

Veneto Tumour Registry,

Passaggio Gaudenzio 1,

Padova (PD) 35131, Italy;

manuel.zorzi@regione.veneto.it

Received 2 July 2014

Revised 8 August 2014

Accepted 31 August 2014

Published Online First

16 September 2014
CrossMark

\footnotetext{
To cite: Zorzi M, Senore C, Da Re F, et al. Gut

2015;64:1389-1396.
}

\section{ABSTRACT}

Objectives To assess variation in the main colonoscopy quality indicators in organised colorectal cancer (CRC) screening programmes based on faecal immunochemical test (FIT).

Design Data from a case-series of colonoscopies of FIT-positive subjects were provided by 44 Italian CRC screening programmes. Data on screening history, endoscopic procedure and histology results, and additional information on the endoscopy centre and the endoscopists were collected. The adenoma detection rate (ADR) and caecal intubation rate (CIR) were assessed for the whole population and the individual endoscopists. To explore variation in the quality indicators, multilevel analyses were performed according to patient/centre/ endoscopist characteristics.

Results We analysed 75569 (mean age: 61.3 years; men: $57 \%$ ) colonoscopies for positive FIT performed by 479 endoscopists in 79 centres. ADR ranged from $13.5 \%$ to $75 \%$ among endoscopists (mean: $44.8 \%$ ). ADR was associated with gastroenterology specialty (OR: 0.87 for others, $95 \% \mathrm{Cl} 0.76$ to 0.96$)$ and, at the endoscopy centre level, with the routine use of sedation (OR: 0.80 if occasional $(<33 \%) ; 95 \% \mathrm{Cl} 0.64$ to 1.00$)$ and availability of screening-dedicated sessions (OR: 1.35; $95 \% \mathrm{Cl} 1.11$ to 1.66). CIR ranged between $58.8 \%$ and $100 \%$ (mean: $93.1 \%$ ). Independent predictors of CIR at the endoscopist level were the yearly number of screening colonoscopies performed (OR: 1.51 for endoscopists with $>600$ colonoscopies; $95 \% \mathrm{Cl} 1.11$ to 2.04) and, at the endoscopy centre level, screeningdedicated sessions (OR: 2.18; $95 \% \mathrm{Cl} 1.24$ to 3.83 ) and higher rates of sedation (OR: 0.47 if occasional; $95 \% \mathrm{Cl}$ 0.24 to 0.92 ).

Conclusions The quality of colonoscopy was affected by patient-related, endoscopist-related and centre-related characteristics. Policies addressing organisational issues should improve the quality of colonoscopy in our programme and similar programmes.

\section{INTRODUCTION}

Colorectal cancer (CRC) is a major cause of morbidity and mortality. ${ }^{12}$ CRC screening with biannual

\section{Significance of this study}

What is already known on this subject?

- Organised colorectal cancer screening programmes with immunochemical faecal test have been implemented in Europe.

- The quality of colonoscopy is critical for the overall success of these organised programmes.

- Adenoma detection rate and caecal intubation rate are the most important indicators of the quality of colonoscopy.

What are the new findings?

- In the Italian screening programme with immunochemical faecal test, the overall level of quality of colonoscopy was adequate, with the adenoma detection and caecal intubation rates being $45 \%$ and $93 \%$, respectively.

- There was substantial variation among the endoscopists in both indicators. This variation was explained by at least three levels of predictors, namely at per-patient, per-endoscopist and per-centre levels.

- Gastroenterology specialty, sedation and the availability of screening-dedicated sessions were associated with the adenoma detection rate. Sedation, the availability of screeningdedicated sessions and the volume of screening colonoscopies were associated with the caecal intubation rate.

How might it impact on clinical practice in the foreseeable future?

- Policies addressing organisational issues, such as sedation, the availability of screening sessions and endoscopist retraining are likely to improve the overall quality of colonoscopy in this setting.

faecal occult blood test (FOBT) has been shown to reduce CRC mortality, ${ }^{3} 4$ and immunochemicalFOBT (faecal immunochemical test, FIT) has been shown to be more accurate than guaiac-FOBT 
(g-FOBT) for advanced neoplasia. ${ }^{5}$ An organised screening programme with FIT has been implemented in Italy ${ }^{7}$ as well as in other European countries and Australia. ${ }^{8}$ The efficacy of an FOBT-based screening programme ultimately depends on the accuracy of post-FOBT colonoscopy. High variability in the adenoma detection rate (ADR) between endoscopists has been reported, and $\mathrm{ADR}$ predicts the risk of postcolonoscopy interval cancer. $^{9-14}$ The indication of positive FOBT is an independent predictor of interval cancer after colonoscopy, ${ }^{15}$ reflecting the high prevalence of advanced neoplasia in FIT-positive patients and underscoring the need for effective detection at colonoscopy in this population. ${ }^{5} 16$ The caecal intubation rate (CIR) is also an important indicator of colonoscopy quality, as lower rates are associated with increased risk of postcolonoscopy cancer. ${ }^{12} 15$

A previous study on 36460 colonoscopies performed within the National Health Service Bowel Cancer Screening Programme with g-FOBT demonstrated a marked variation in ADR among 177 endoscopists, ranging between 21.9\% and $59.8 \% .{ }^{17}$ However, endoscopist-related/centre-related predictors of variable detection were not explored at multivariate analysis. ${ }^{17}$ Predictors of CIR within an organised screening programme have not been assessed, and no previous study has reported detection variation in a programme based on FIT.

We assessed variation in colonoscopy quality among the endoscopists operating within the organised screening programme with FIT in Italy, and identified endoscopist and centre-related factors that affect ADR and CIR.

\section{MATERIALS AND METHODS}

\section{CRC-organised screening programme in Italy}

The organised screening programme with FIT in Italy is performed at a regional level. Screening centres in each region are responsible for inviting eligible subjects. In 2010, overall 107 centres were active in Italy, with a target population of 9493250 50-year-old to 69-year-old persons. Programs invite people (mostly aged 50-69 years) to perform a single-sample FIT on a biennial basis; only in the Piedmont region and in the province of Verona, people aged 58 or 60 years (Verona) are offered screening with flexible sigmoidoscopy (FS) once in the lifetime, while biennial FIT is offered until age 69 years to those who are not screened with FS. Due to heterogeneity in resources, the screening programme has been mainly implemented in the North-Central Italian regions. ${ }^{7}$ Individuals with a positive FIT result (cut-off=100 ng HB/mL buffer) are offered colonoscopy. Persons attending colonoscopy are required to give preprocedure consent and are given explicit instructions on bowel preparation. Sedation and bowel preparation are performed in accordance with local guidelines, which vary among screening centres. All demographic, colonoscopic and histopathological data are recorded by the screening centre on a regional database. There is no established accreditation programme or examination and/or audit, for an endoscopist to practise in the organised screening programme.

\section{Study population}

All the organised CRC screening programmes in Italy were invited to participate in this study. Each participating programme was required to provide individual data about all colonoscopies carried out within the regional screening programmes during 2010. Depending on data availability, individual programmes, or regions, could provide additional data referring to other calendar years.

For each patient, demographic information, screening history and colonoscopic procedure and histology results were collected on a standard precoded electronic form. Information
Table 1 Explicative variables for the adenoma detection rate

\begin{tabular}{|c|c|c|}
\hline $\begin{array}{l}\text { Patient } \\
\text { characteristics }\end{array}$ & $\begin{array}{l}\text { Endoscopist } \\
\text { characteristics }\end{array}$ & $\begin{array}{l}\text { Endoscopic Centre } \\
\text { characteristics }\end{array}$ \\
\hline $\begin{array}{l}\text { Sex } \\
\text { Age } \\
\text { FIT round } \\
\text { Bowel } \\
\text { cleansing } \\
\text { Caecal } \\
\text { intubation }\end{array}$ & $\begin{array}{l}\text { Sex } \\
\text { Age } \\
\text { Specialty } \\
\text { Number of years of } \\
\text { activity as endoscopist } \\
\text { Number of screening TCs } \\
\text { performed in } 2010 \\
\text { Overall number of TCs } \\
\text { performed in } 2010\end{array}$ & $\begin{array}{l}\text { Use of dedicated } \\
\text { sessions } \\
\text { Use of sedation } \\
\text { Number of screening TCs } \\
\text { performed in } 2010\end{array}$ \\
\hline
\end{tabular}

concerning the endoscopy centre (EC) and the endoscopists were collected based on a standard form (table 1).

In order to reduce variation in the baseline prevalence of lesions and to avoid double-counting of adenomas, only first colonoscopies following a positive FIT were included in the analysis.

\section{Study variables}

At the patient level, individual colonoscopy data routinely included the following information: (1) patient demographics, (2) number of previous FIT examinations, (3) quality of bowel preparation (endoscopist's judgement, aggregated as adequate/ inadequate), (4) sedation (conscious/deep/none), (5) caecal intubation and (6) number and characteristics of diagnosed polyps/masses, including morphology, localisation, size and histology. In detail, due to the heterogeneity of bowel preparation scales adopted in the different programmes, participating centres were asked to record bowel cleansing, according to a 4categories scale (excellent, good, fair, poor) that was subsequently aggregated as adequate (excellent/good) and inadequate (fair/poor).

At the endoscopist level, we collected (1) demographics, (2) specialty, (3) number of years of activity as endoscopist $(\leq 5,6-9$, $\geq 10$-year experience), (4) number of screening colonoscopies performed in $2010(\leq 100,101-180,>180)$ and $(5)$ overall number of colonoscopies performed in 2010 ( $\leq 300,301-600$, $>600)$.

At the centre level, we collected the following indicators: (1) use of screening-dedicated sessions for FIT-positive colonoscopies (ie, scheduled outside daily non-screening endoscopy), (2) use of sedation $(<33 \%, 33 \%-66 \%$ and $>66 \%$ of colonoscopies), (3) adoption of routine quality assurance procedures (ie, monitoring of postprocedural complications, documentation of caecal intubation, scale used to assess quality of bowel preparation). Based on the 2010 data, we also calculated the number of post-FIT-positive colonoscopies performed in $2010(\leq 300$, 301-600, 601-800 and >800).

\section{Study end-points and statistical analysis}

In order to assess the variability in the detection rate among individual endoscopists, we aggregated the diagnosis of the following findings at a per-patient level: (1) polyp (polyp detection rate, PDR), (2) ADR, (3) advanced adenoma detection rate (an adenoma with villous component $>20 \%$, or high-grade dysplasia, or size $\geq 1 \mathrm{~cm}-\mathrm{AADR}$ ).

We used linear regression to assess correlation between ADR on one side and PDR/AADR on the other. In order to identify possible predictors of ADR, we evaluated the association between several variables and ADR. These variables were 
classified as characteristics of (1) patient, (2) EC and (3) endoscopist (table 1). Sedation was considered as an organisation modality of the EC.

We initially explored the relationship between each group of variables and ADR by univariate analysis. The variables with a significant association with detection were included in a multivariate model with $\mathrm{SE}$ correction. Finally, the variables that remained associated with detection rates were included in a final multilevel model (with Laplace approximation), that accounted for the intralevel and interlevel variability at the following levels: region, EC and endoscopist. The Variance Partition Coefficient was used to quantify the proportion of the residual outcome variation attributable to unobserved characteristics of each level of the model. ${ }^{18} 19$

We performed the same analysis for predictors of CIR, excluding colonoscopies with inadequate cleansing. Indeed, the examination might have been interrupted already during the insertion phase in these cases, if the endoscopist had judged the preparation inadequate, since the colonoscopy needed to be repeated in any case. However, we also added inadequate cleansing as a putative predictor of CIR in a secondary analysis.

All reported $\mathrm{p}$ values are two sided. A p value of $<0.05$ was considered significant. All analyses were performed using Stata V.10.0 statistical package.

\section{RESULTS}

\section{Study population}

Overall, 44 programmes from eight regions of Northern and Central Italy took part in the study, with an overall target population of 403646950 69-year-old persons. All programmes used the OC-Hemodia latex agglutination test, developed with the OC-Sensor Diana or OC-Sensor Micro instrument (Eiken, Tokyo, Japan). These programmes provided individual data on 93249 colonoscopies included in the CRC database in 2010. Of these, $75569(81 \%)$ were for positive FIT, the remaining being for postpolypectomy surveillance $(n=12$ 902, 13.8\%), completion of previously incomplete colonoscopies $(n=2483$, $2.7 \%)$ or other screening-related indications $(n=2295,2.5 \%)$. Thus, the final study population consisted of 75569 patients (mean age: 61.3 years; men: 57\%). The geographical distribution of the study population is provided in table 2 .

\section{Patient characteristics}

Overall, 43430 (57.5\%) positives were at the first FIT examination, and the remaining patients had one or more previous negative FIT exams (table 2). Sedation was applied in $81.7 \%$ of the cases. When reported $(n=25760,41.7 \%)$, it was conscious sedation in most cases (89.6\%). Caecal intubation was achieved in $93.1 \%$ of the patients. Colon cleansing was rated adequate in $92.7 \%$ of the patients.

\section{Endoscopist characteristics}

The endoscopist's characteristics were available for $73 \%$ of endoscopists (350/479), accounting for 85.6\% of (64686/ 75 569) colonoscopies. In the remaining cases, the endoscopist's identification code was recorded, but his/her characteristics were not provided. As shown in table 3, 76.5\% of the exams were performed by male endoscopists, and $42.9 \%$ by operators between 50 and 59 years of age. The majority of the colonoscopies $(73.8 \%)$ were performed by gastroenterologists, with the remaining by surgeons or other specialties. Distribution of endoscopists/colonoscopies according to experience/volume of procedures is provided in table 3. More than 63\% endoscopists had over 10 years of experience.
Table 2 Main characteristics of the study population and of the colonoscopies included in the study

\begin{tabular}{|c|c|c|}
\hline Variable & Number & Per cent \\
\hline Overall & 75569 & 100 \\
\hline \multicolumn{3}{|l|}{ Region } \\
\hline Emilia Romagna & 15891 & 21.0 \\
\hline Lazio & 3268 & 4.3 \\
\hline Liguria & 487 & 0.6 \\
\hline Marche & 2584 & 3.4 \\
\hline Piemonte & 891 & 11.8 \\
\hline Toscana & 5024 & 6.7 \\
\hline Trento & 1171 & 1.6 \\
\hline Veneto & 38234 & 50.6 \\
\hline \multicolumn{3}{|l|}{ Sex } \\
\hline Male & 42965 & 56.9 \\
\hline Female & 32603 & 43.1 \\
\hline Missing & 1 & 0 \\
\hline \multicolumn{3}{|l|}{ Age (years) } \\
\hline 50-55 & 13241 & 17.5 \\
\hline $55-59$ & 13842 & 18.3 \\
\hline $60-64$ & 21163 & 28 \\
\hline $65+$ & 27313 & 36.1 \\
\hline Missing & 10 & 0 \\
\hline \multicolumn{3}{|l|}{ FIT round } \\
\hline $1 s t$ & 43430 & 57.5 \\
\hline 2nd & 19149 & 25.3 \\
\hline $3 r d$ & 9516 & 12.6 \\
\hline$\geq 4$ th & 2948 & 3.9 \\
\hline Missing & 526 & 0.7 \\
\hline \multicolumn{3}{|l|}{ Bowel cleansing } \\
\hline Adequate & 70026 & 92.7 \\
\hline Inadequate & 5218 & 6.9 \\
\hline Missing & 325 & 0.4 \\
\hline \multicolumn{3}{|l|}{ Caecal intubation } \\
\hline Yes & 70374 & 93.1 \\
\hline No & 4946 & 6.6 \\
\hline Missing & 249 & 0.3 \\
\hline \multicolumn{3}{|l|}{ Sedation } \\
\hline Done* & 36013 & 47.7 \\
\hline Conscious & 23090 & 30.6 \\
\hline Propofol & 2670 & 3.5 \\
\hline None & 13720 & 18.2 \\
\hline Missing & 76 & 0.1 \\
\hline
\end{tabular}

\section{ECs' characteristics}

EC information was available for 79 centres, accounting for $88 \%$ (66 539/75 569) of the study colonoscopies. In $81 \%$ of the 79 centres, colonoscopy for positive FITs was performed in dedicated sessions, accounting for $87.5 \%$ of the procedures (table 4 ). Sedation was used in $>66 \%$ of colonoscopies in 60 ECs $(75 \%)$, accounting for $51068(82.4 \%)$ procedures. Sedation was performed in $33 \%-66 \%$ and $<33 \%$ of colonoscopies in $11(13.8 \%)$ and $9(11.3 \%)$ centres, respectively. Distribution of centres according to the volume of yearly screening colonoscopies and endoscopist specialty is reported in table 4.

\section{Adenoma detection rates}

At a per-patient analysis, at least one polyp/adenoma/advanced adenoma was in $59.3 \%, 44.8 \%$ and $29 \%$ of the procedures. 
Table 3 Main characteristics of the study endoscopists $(n=350)$ and FIT+colonoscopies performed by the different endoscopists

\begin{tabular}{|c|c|c|c|}
\hline Variable & $\begin{array}{l}\text { Number of } \\
\text { endoscopists }\end{array}$ & Per cent & Colonoscopies (\%) \\
\hline \multicolumn{4}{|l|}{ Sex } \\
\hline Male & 253 & 72.3 & 76.5 \\
\hline Female & 97 & 27.7 & 23.5 \\
\hline \multicolumn{4}{|l|}{ Age (years) } \\
\hline 30-39 & 71 & 20.3 & 16.4 \\
\hline $40-49$ & 89 & 25.4 & 25.0 \\
\hline $50-59$ & 135 & 38.6 & 42.9 \\
\hline$\geq 60$ & 44 & 12.6 & 13.8 \\
\hline Missing & 11 & 3.1 & 1.9 \\
\hline \multicolumn{4}{|l|}{ Specialty } \\
\hline Gastroenterology & 253 & 72.3 & 73.8 \\
\hline Surgery & 77 & 22.0 & 21.2 \\
\hline Other & 13 & 3.7 & 3.6 \\
\hline Missing & 7 & 2.0 & 1.4 \\
\hline \multicolumn{4}{|l|}{ Experience (years) } \\
\hline$\leq 5$ & 43 & 12.3 & 7.0 \\
\hline $6-9$ & 56 & 16.0 & 15.8 \\
\hline$\geq 10$ & 222 & 63.4 & 70.1 \\
\hline Missing & 29 & 8.3 & 7.2 \\
\hline \multicolumn{4}{|c|}{ Screening colonoscopies performed in 2010} \\
\hline$\leq 100$ & 281 & 80.3 & 50.9 \\
\hline $101-180$ & 47 & 13.4 & 25.7 \\
\hline$>180$ & 22 & 6.3 & 23.4 \\
\hline \multicolumn{4}{|c|}{ Overall colonoscopies performed in 2010} \\
\hline$\leq 300$ & 76 & 21.7 & 10.1 \\
\hline $301-600$ & 120 & 34.3 & 31.5 \\
\hline$>600$ & 123 & 35.1 & 54.5 \\
\hline Missing & 31 & 8.9 & 3.9 \\
\hline
\end{tabular}

ADR of single endoscopists was strongly correlated with both PDR and AADR (figure 1).

ADR ranged from $13.5 \%$ to $75 \%$ among endoscopists who performed at least 30 colonoscopies, the 10 th and 90th percentile of ADR among endoscopists being $31.9 \%$ and $60 \%$.

Table 4 Main characteristics of the endoscopic centres and FIT+ colonoscopies performed by endoscopic centres with different characteristics

\begin{tabular}{|c|c|c|c|}
\hline Variable & $\begin{array}{l}\text { Number of } \\
\text { endoscopic centres }\end{array}$ & Per cent & Colonoscopies (\%) \\
\hline \multicolumn{4}{|c|}{ Screening-dedicated sessions } \\
\hline Yes & 64 & 81.0 & 87.5 \\
\hline No & 15 & 19.0 & 12.6 \\
\hline \multicolumn{4}{|c|}{ Colonoscopy with sedation/all colonoscopies } \\
\hline$<33 \%$ & 8 & 10.2 & 7.1 \\
\hline $33 \%-66 \%$ & 11 & 13.9 & 10.5 \\
\hline$>66 \%$ & 60 & 75.9 & 82.4 \\
\hline \multicolumn{4}{|c|}{ Screening colonoscopies performed in 2010} \\
\hline$\leq 300$ & 54 & 68.4 & 26.5 \\
\hline $301-600$ & 12 & 15.2 & 26.0 \\
\hline $601-800$ & 7 & 8.9 & 26.9 \\
\hline$>800$ & 6 & 7.6 & 20.5 \\
\hline \multicolumn{4}{|c|}{$\begin{array}{l}\text { Screening-dedicated sessions are defined as endoscopic session restricted to } \\
\text { screening-related colonoscopies. } \\
\text { FIT, faecal immunochemical test. }\end{array}$} \\
\hline
\end{tabular}

Regarding patient characteristics, ADR was higher in men, those examined in the first FIT screening round, those with adequate bowel preparation, and it showed a trend toward increasing with older age (table 5).

ADR was associated with endoscopist specialty, but not with endoscopist years of experience or the volume of activity. ADR was higher in centres with dedicated sessions and in those that routinely used sedation.

In the multilevel analysis (table 6), ADR was associated with the following factors: (1) Patient-related, male sex (OR of women: $0.58,95 \%$ CI 0.56 to 0.60 ), age (OR: 1.02 per 1 -year increase, $95 \%$ CI 1.02 to 1.03 ), 1st FIT round (OR: 0.78 per 1-round increase, $95 \%$ CI 0.75 to 0.81 ), complete colonoscopy (OR: $2.52,95 \%$ CI 2.32 to 2.75 ) and an adequate preparation (OR: 1.53 , 95\% CI 1.42 to 1.65); (2) Endoscopist-related, gastroenterology specialty (OR of other specialties: $0.87,95 \%$ CI 0.76 to 0.96 ); (3) EC-related, routine use of sedation (OR of occasional $(<33 \%)$ use: $0.80,95 \%$ CI 0.64 to 1.00$)$ and screening-dedicated session (OR: $1.35,95 \%$ CI 1.11 to 1.66 ).

The residual variation was $1.1 \%$ both at the endoscopist and EC levels; no residual variability was observed at the region level.

When restricting the analysis to subjects with complete colonoscopy (data not shown) the predictive role of the other variables did not show substantial changes.

\section{Caecal intubation rate}

Overall, the caecum was reached in $93.1 \%$ of colonoscopies. CIR was slightly lower in female patients and in those examined in their first FIT round, and it decreased with age (table 5). CIR dropped to $71.3 \%$ in cases with inadequate bowel cleansing. CIR was higher for endoscopists with more than 5 years of experience, and in those performing a high volume of examsboth screening and overall. CIR ranged between $58.8 \%$ and $100 \%$ among endoscopists who had performed at least 30 colonoscopies (10th-90th percentile: $83.3 \%$ and 99.7\%).

Among the organisational characteristics of ECs, CIR was higher when the exam was performed in dedicated sessions (94.3\%) than in colonoscopies without dedicated sessions $(90.6 \%)$, in centres with a higher proportion of sedated exams $(94.5 \%)$ than in those performing sedation in $<33 \%$ of colonoscopies and in those with a higher yearly volume of colonoscopies, compared with those with lower volumes.

At the multilevel analysis, CIR was lower in women (OR of women: 0.72 , 95\% CI 0.66 to 0.78 ), older age (OR per 1-year increase: $0.97,95 \%$ CI 0.97 to 0.98 ), while it was higher in subjects at subsequent screening round (OR per 1-round increase: 1.42, 95\% CI 1.27 to 1.58 ) (table 7). Among endoscopist characteristics, caecal intubation was associated with the yearly number of screening colonoscopies performed (OR 1.38, 95\% CI 1.04 to 1.82 and $1.51,95 \%$ CI 1.11 to 2.04 for endoscopists with 301-600 and $>600$ colonoscopies, respectively). Screening-dedicated sessions were associated with a doubling of completion of colonoscopy too (OR: 2.18 , 95\% CI 1.24 to 3.83), while low rates of sedation reduced CIR by more than 50\% (OR: $0.47,95 \%$ CI 0.24 to 0.92 ). The residual unexplained variability for CIR was $2.4 \%, 8.5 \%$ and $7.1 \%$ for the region, EC and endoscopist levels, respectively.

When persons with inadequate bowel cleansing were included, the predictive role of the other variables did not show substantial changes (data not shown), while adequate cleansing was strongly associated with CIR (OR 9.94, 95\% CI 9.07 to 10.9).

\section{DISCUSSION}

Our data indicate that variation in quality of colonoscopy performance in an organised screening programme with FIT is 
Figure 1 Linear regression of the polyp detection rate and advanced adenoma detection rate with the adenoma detection rate of single endoscopists.

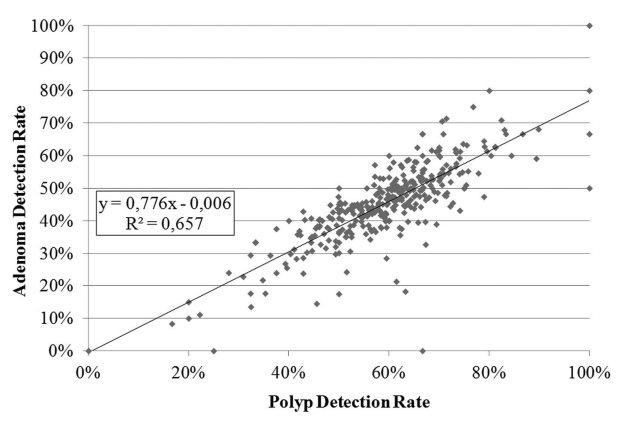

largely explained by relatively simple endoscopist and organisational characteristics. We showed that dedicated colonoscopy sessions and systematic use of sedation predicted higher ADR and CIR in our study population. Additionally, the CIR of individual endoscopists is predicted by the yearly volume of colonoscopies performed in the programme, and gastroenterologists have higher ADRs.

The very low proportion of the total variance of each level suggests that nearly all the variability in ADR between endoscopists and ECs is explained by the factors included as fixed effects in the model. The absence of residual variability at the regional level might be related to the very low variability in the incidence rate in the areas involved in the study. ${ }^{20}$

The proportion of variability in CIR attributable to unobserved characteristics was lower than $10 \%$ both between endoscopists and between ECs.

This is the first study assessing the quality of colonoscopy-as measured by ADR and CIR-within an organised screening programme with FIT. While the mean values reported in our cohort indicate an adequate average quality of colonoscopy (mean ADR and CIR of 45\% and 93\%, respectively), we also identified substantial variability among endoscopists, the ADR and CIR ranging between $13 \%$ and $75 \%$, and $59 \%$ and $100 \%$, respectively. Our data, based on 75569 FIT-positive colonoscopies, confirm the large variation in ADR observed in a cohort of 36460 g-FOBT-positive patients in the UK, with the endoscopist-ADR and CIR ranging between $22 \%$ and $60 \%$, and between $76 \%$ and $100 \%$, respectively. ${ }^{17}$

Additionally, our multilevel analysis showed that ADR and CIR should be considered as multidimensional quality indicators, depending on at least three different levels of the screening process, namely the patient, the endoscopist and the centre. Of note, we were able to identify significant predictors at each of these levels. We showed that age, sex and round of FIT are each independent patient-related predictive factors of neoplasia detection. This differed from the g-FOBT setting, where round of screening did not affect endoscopist ADR. ${ }^{17}$ This difference could be related to the higher sensitivity of FIT for large adenomas compared with g-FOBT, resulting in a net decrease in ADR between the first and subsequent rounds, as already showed in the Dutch and Italian studies. ${ }^{21} 22$ Similarly, we showed that female sex was strongly associated with a lower CIR, in agreement with a previous study. ${ }^{23}$ Additionally, we showed a dramatic impact of the level of cleansing on ADR. This is different from the previous UK g-FOBT-based study where, unexpectedly, no difference in ADR according to level of cleansing was shown. ${ }^{22}$ Our result is in line with several studies, relating adequate preparation to higher ADR. ${ }^{24} 25$ This finding underscores the value of implementing policies to improve cleansing within organised screening programmes. In particular, all barriers to split regimens should be removed, considering the favourable effect of this simple adjustment on cleansing level and ADR. ${ }^{26} 27$ Inadequate preparation was also associated with a substantially lower CIR, in agreement with previous reports. $^{28} 29$

GI-specialty was an independent predictor of ADR at an endoscopist's level. Despite the association between endoscopist-specialty and ADR not having been explored previously, ${ }^{17} 30{ }^{31}$ GI-specialty has been consistently related with a reduced risk of postcolonoscopy interval cancer. ${ }^{10}$ 32-35 $\mathrm{No}$ study that examined this issue has found colonoscopy by nongastroenterologists to be as or more effective in preventing CRC compared with colonoscopy by gastroenterologists. ${ }^{10} 32-36$ One potential conclusion is to transfer the performance of colonoscopy from non-gastroenterologists to gastroenterologists. A recent study found that substantial differences in polyp detection existed between gastroenterology and surgical trainees in the same institution. ${ }^{37}$ We also showed an association between the volume of screening colonoscopy and the CIR, underlining the relevance of an adequate volume of procedures on the overall quality of colonoscopy.

Third, we showed that organisational features of ECs affect $\mathrm{ADR}$ and CIR in organised screening programmes.

In particular, sessions dedicated to colonoscopy in FIT-positive patients were associated with better performance for both quality measures. To our knowledge, this variable has not been examined in previous series. Dedicated sessions may reduce distractions for endoscopists, allow scheduling adjustments for the relatively heavy polyp burdens of FIT-positive patients, and encourage specialisation and development of expertise in colonoscopy and polypectomy, such as is commonly perceived to occur in endoscopy lists concentrated on procedures such as endoscopic ultrasound, endoscopic retrograde cholangiopancreatography, treatment of Barrett's oesophagus, and surveillance of inflammatory bowel disease. Dedicated sessions for FIT-positive patients are attractive from the perspective of being relatively simple to arrange, requiring only reallocation of resources rather than new medical or economic and logistic resources.

The large sample size allowed us to show an association between the use of sedation, and higher ADR and CIR. The association between sedation and CIR shown by our analysis is in agreement with previous reports. ${ }^{26} 38$ The evidence of the effect of any sedation on ADR is limited and inconsistent. Our findings are in line with a previous nationwide Italian study reporting an association between sedation and higher PDR in a cohort of unselected patients who underwent sedated colonoscopy in $55 \%$ of the cases. ${ }^{29}$ On the other hand, effect of sedation on ADR was found in the g-FOBT-based UK cohort, as well as in other screening studies. ${ }^{24}{ }^{38-41}$ The high proportion of sedated exams in some of these studies (ie, $>95 \%$ in the Spanish study ${ }^{27}$ ) might explain the lack of an association between sedation and ADR. The proportion of unsedated exams, as well as the interendoscopist variability in sedation use, 
Table 5 Adenoma detection rate (\%) and caecal intubation rate (\%) per patient, endoscopist and centre levels, with 95\% Cls

\begin{tabular}{|c|c|c|c|c|}
\hline \multirow[b]{2}{*}{ Variable } & \multicolumn{2}{|c|}{ Adenoma detection rate } & \multicolumn{2}{|c|}{ Caecal intubation rate } \\
\hline & $\%(95 \% \mathrm{Cl})$ & Number & $\%(95 \% \mathrm{Cl})$ & Numbe \\
\hline Overall & 44.8 (44.5 to 45.2 ) & 75569 & 93.4 (93.3 to 93.6$)$ & 75320 \\
\hline \multicolumn{5}{|c|}{ Patient characteristics } \\
\hline \multicolumn{5}{|c|}{ Sex } \\
\hline Male & 50.6 (50.1 to 51.0$)$ & 42823 & 94.1 (93.9 to 94.4 ) & 42833 \\
\hline Female & 37.3 (36.7 to 37.8 ) & 32462 & 92.5 (92.2 to 92.8$)$ & 32486 \\
\hline \multicolumn{5}{|l|}{ Age (years) } \\
\hline $50-54$ & 39.4 (38.8 to 40.5$)$ & 19416 & 94.7 (94.2 to 95.1$)$ & 12358 \\
\hline $55-59$ & 44.6 (43.3 to 44.9 ) & 12113 & 94.2 (93.9 to 94.6$)$ & 13778 \\
\hline $60-64$ & 46.8 (45.8 to 47.1 ) & 18742 & 93.3 (93.0 to 93.7 ) & 21103 \\
\hline $65+$ & 46.8 (46.1 to 47.3 ) & 25005 & 92.5 (92.2 to 92.8 ) & 27233 \\
\hline \multicolumn{5}{|l|}{ FIT round } \\
\hline 1st & 47.2 (46.7 to 47.6 ) & 40193 & 92.8 (92.6 to 93.0$)$ & 43274 \\
\hline 2 nd & 42.7 (42.0 to 43.4 ) & 19149 & 94.3 (94.0 to 94.6 ) & 19074 \\
\hline $3 r d$ & 40.4 (39.4 to 41.4$)$ & 9516 & 94.6 (94.1 to 95.0$)$ & 9507 \\
\hline$\geq 4$ th & 40.5 (38.7 to 42.2 ) & 2948 & 94.7 (93.9 to 95.5 ) & 2942 \\
\hline \multicolumn{5}{|l|}{ Bowel cleansing } \\
\hline Adequate & 45.8 (45.4 to 46.1 ) & 69765 & 95.0 (94.9 to 95.2$)$ & 69975 \\
\hline Inadequate & 33.7 (32.2 to 34.7$)$ & 5195 & 71.9 (70.4 to 83.0$)$ & 5169 \\
\hline
\end{tabular}

\section{Endoscopist characteristics}

Sex

Male $\quad 44.7(44.2$ to 45.1$) 49492 \quad 93.9$ (93.7 to 94.1) 49416

Female $\quad 46.8(46.0$ to 47.5$) \quad 15194 \quad 94.3$ (94.0 to 94.7) 15180

Age (years)

30-39 47.1 (46.2 to 48.1) $10602 \quad 94.0$ (93.6 to 94.5) 10589

40-49 $\quad 45.3$ (44.6 to 46.1$) \quad 16169 \quad 94.1$ (93.7 to 94.4) 16158

50-59 44.7 (44.2 to 45.3) $27775 \quad 93.9$ (93.6 to 94.2) 27745

$\begin{array}{llll}\geq 60 & 43.6(42.6 \text { to } 44.6) \quad 8902 \quad 94.3 \text { (93.9 to } 94.8) \quad 8879\end{array}$

Specialty

Gastroenterology 46.1 (45.6 to 46.5 ) $47751 \quad 94.1$ (93.9 to 94.3) 47707 Surgery $\quad 42.7$ (41.9 to 43.5$) \quad 13723 \quad 93.9$ (93.5 to 94.3) 13693 Other $\quad 42.7(40.7$ to 44.7$) \quad 2337 \quad 94.1$ (93.1 to 95.1$) \quad 2324$

Experience (years)

$\begin{array}{llrlr}\leq 5 & 45.8(44.4 \text { to } 47.2) & 4508 & 92.2(91.4 \text { to } 93.0) & 4507 \\ 6-9 & 44.2(43.2 \text { to } 45.2) & 10219 & 94.4(94.0 \text { to } 94.9) & 10216 \\ \geq 10 & 45.2(44.8 \text { to } 45.7) & 45333 & 94.0(93.8 \text { to } 94.2) & 45273\end{array}$

Screening colonoscopies performed in 2010

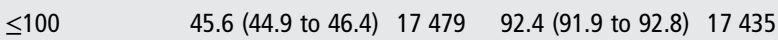

101-180 46.2 (45.5 to 46.9) $18102 \quad 94.7$ (94.3 to 95.0) 18082

$>180 \quad 44.8$ (44.2 to 45.5$) \quad 23484 \quad 95.6$ (95.3 to 95.8) 23461

Overall colonoscopies performed in 2010

$\begin{array}{llrlr}\leq 300 & 42.3(41.1 \text { to } 43.5) & 6545 & 90.3(89.6 \text { to } 91.0) & 6538 \\ 301-600 & 46.5(45.8 \text { to } 47.2) & 20379 & 93.7(93.4 \text { to } 94.0) & 20367 \\ >600 & 45.0(44.4 \text { to } 45.5) & 35236 & 95.0(94.8 \text { to } 95.2) & 35201\end{array}$

Endoscopic centre characteristics

Screening-dedicated sessions

Yes $\quad 46.0(45.6$ to 46.4$) \quad 58189 \quad 94.4(94.2$ to 94.6$) 58113$

No $\quad 38.2$ (37.1 to 39.2$) \quad 8350 \quad 89.9$ (89.3 to 90.6) 8320

Colonoscopies with sedation/all colonoscopies

$\begin{array}{llllll}<33 \% & 38.7(37.3 \text { to } 40.1) & 4830 & 86.8(85.8 \text { to } 87.7) & 4826\end{array}$

$33 \%-66 \% \quad 44.3$ (43.1 to 45.4$) \quad 7165 \quad 93.4$ (92.8 to 93.9$) \quad 7145$

$>66 \% \quad 45.5$ (45.1 to 45.9$) \quad 56086 \quad 94.5$ (94.3 to 94.7) 55878

Screening colonoscopies performed in 2010

$\leq 300 \quad 44.2$ (43.5 to 45.0$) \quad 17658 \quad 90.8$ (90.4 to 91.2) 17592

301-600 $\quad 44.9(44.2$ to 45.6$) \quad 17310 \quad 95.8(95.5$ to 96.1$) \quad 17271$

601-800 $\quad 44.4$ (43.7 to 45.2$) \quad 17912 \quad 94.3$ (94.0 to 94.6) 17911

$>800 \quad 47.0(46.1$ to 47.8$) \quad 13659 \quad 94.5$ (94.2 to 94.9$) \quad 13659$

FIT, faecal immunochemical test.
Table 6 Multilevel multivariate analysis to identify predictors of the adenoma detection rate in the study population

\begin{tabular}{|c|c|c|c|}
\hline & OR & $95 \% \mathrm{Cl}$ & $\mathrm{p}$ Value \\
\hline \multicolumn{4}{|l|}{ Patient characteristics } \\
\hline \multicolumn{4}{|l|}{ Sex } \\
\hline Male* & 1.00 & & - \\
\hline Female & 0.58 & 0.56 to 0.60 & $<0.001$ \\
\hline \multicolumn{4}{|l|}{ Age } \\
\hline 1-year increase & 1.02 & 1.02 to 1.03 & $<0.001$ \\
\hline \multicolumn{4}{|l|}{ FIT round } \\
\hline 1-round increase & 0.78 & 0.75 to 0.81 & $<0.001$ \\
\hline \multicolumn{4}{|l|}{ Caecal intubation } \\
\hline $\mathrm{No}^{*}$ & 1.00 & & - \\
\hline Yes & 2.52 & 2.32 to 2.75 & $<0.001$ \\
\hline \multicolumn{4}{|l|}{ Bowel cleansing } \\
\hline Inadequate* & 1.00 & & - \\
\hline Adequate & 1.53 & 1.42 to 1.65 & $<0.001$ \\
\hline \multicolumn{4}{|c|}{ Endoscopist characteristics } \\
\hline \multicolumn{4}{|c|}{ Specialty } \\
\hline Gastroenterology* & 1.00 & & - \\
\hline Others & 0.87 & 0.76 to 0.96 & 0.01 \\
\hline \multicolumn{4}{|c|}{ Endoscopic centre characteristics } \\
\hline \multicolumn{4}{|c|}{ Colonoscopy with sedation/all colonoscopies } \\
\hline$>66 \% *^{*}$ & 1.00 & & - \\
\hline $33 \%-66 \%$ & 0.92 & 0.76 to 1.11 & 0.38 \\
\hline$<33 \%$ & 0.80 & 0.64 to 1.00 & 0.05 \\
\hline \multicolumn{4}{|c|}{ Screening-dedicated sessions } \\
\hline $\mathrm{No}^{*}$ & 1.00 & & - \\
\hline Sì & 1.35 & 1.11 to 1.66 & 0.001 \\
\hline
\end{tabular}

Table 7 Multilevel analysis to identify predictors of caecal intubation in the study population

\begin{tabular}{|c|c|c|c|}
\hline & OR & $95 \% \mathrm{Cl}$ & p Value \\
\hline \multicolumn{4}{|l|}{ Patient characteristics } \\
\hline \multicolumn{4}{|l|}{ Sex } \\
\hline Male* & 1.00 & & - \\
\hline Female & 0.72 & 0.66 to 0.78 & $<0.001$ \\
\hline \multicolumn{4}{|l|}{ Age } \\
\hline 1-year increase & 0.97 & 0.97 to 0.98 & $<0.001$ \\
\hline \multicolumn{4}{|l|}{ FIT round } \\
\hline 1-round increase & 1.42 & 1.27 to 1.58 & $<0.001$ \\
\hline \multicolumn{4}{|c|}{ Endoscopist characteristics } \\
\hline \multicolumn{4}{|c|}{ Screening colonoscopies performed in 2010} \\
\hline$\leq 300$ & 1.00 & & - \\
\hline $301-600$ & 1.38 & 1.04 to 1.82 & 0.026 \\
\hline$>600$ & 1.51 & 1.11 to 2.04 & 0.008 \\
\hline \multicolumn{4}{|c|}{ Endoscopic centre characteristics } \\
\hline \multicolumn{4}{|c|}{ Colonoscopies with sedation/all colonoscopies } \\
\hline$>66 \%$ * & 1.00 & & - \\
\hline $33 \%-66 \%$ & 1.01 & 0.57 to 1.80 & 0.97 \\
\hline$<33 \%$ & 0.47 & 0.24 to 0.92 & 0.027 \\
\hline \multicolumn{4}{|c|}{ Screening-dedicated sessions } \\
\hline $\mathrm{No}^{*}$ & 1.00 & & - \\
\hline Yes & 2.18 & 1.24 to 3.83 & 0.007 \\
\hline
\end{tabular}


was similar in our study to the UK study. ${ }^{11}{ }^{42}$ The lack of an impact of sedation on ADR in the UK study after adjusting for other factors suggests that technical and organisational factors might reduce the need for sedation without undermining the quality of the examination. The issue of whether sedation or the level of sedation might affect ADR would represent an important research question, in particular, in a screening setting, where patients might prefer to avoid potential risks related to medications.

When considering the variables identified at each of the three levels operating simultaneously, the impact on patients could be dramatic. For example, non-GI endoscopists operating in centres without sedation and screening-dedicated sessions had a threefold lower ADR compared with GI-endoscopists working in an opposite setting. ADR strongly predicts postcolonoscopy interval cancer, ${ }^{13} 1433$ an effect that may be further magnified in the enriched-disease FIT+ population. ${ }^{15}$

We believe the results of our analysis are strengthened by the specific setting in which it was performed. First, patients participating in organised screening programmes are actively invited, so that selection bias due to symptoms is minimised. Second, FIT positivity homogenises the expected prevalence of disease, producing an ideal background to assess endoscopist performance. Third, organised programmes exploit sophisticated software that continuously monitors the performance of the operators/centres at any level, and audits completeness of endoscopic and histological data, so that internal bias is unlikely to occur. ${ }^{7}$ Fourth, although some of the endoscopist-related/ centre-related data were collected prospectively, the endoscopic/ histological data in our FIT programmes was collected retrospectively, so that the endoscopist's performance could not be affected by the psychological awareness of participating in an ADR-based study, the so-called Hawthorne effect. ${ }^{43}$ Fifth, different from the UK screening programme, there is no qualifying examination for Italian endoscopists to participate in the Italian organised screening programmes. ${ }^{17}$ Thus, our study reflects the performance that may be expected in community-based endoscopy.

There are limitations to this analysis. Only 44 out of 107 screening programmes ongoing in Italy took part in the study; that cannot, therefore, be representative of all Italian programmes, in particular of those in Southern Italy. Nevertheless, the large sample size and the population-based setting make our findings applicable to other large scale FIT-based CRC screening programmes. Moreover, CRC incidence rates are similar in Northern as in Central Italy, while they are lower in the South. Thus, the self-exclusion of those programmes increased the homogeneity of the study, by reducing a potential source in ADR variability represented by the different baseline prevalence of the disease.

Since our study was based on volunteer participation by the regional screening programmes, a selection bias cannot be, in theory, excluded. However, participants were required to provide data concerning all total colonoscopy performed among people with a positive FIT result over a prespecified calendar interval. So, as no selection of the examinations to be included in the central data base could be performed by the endoscopists, it seems unlikely that selection bias could affect the main results of our analysis.

We adopted ADR and CIR as surrogate indicators of the quality of colonoscopy, although the ultimate parameter of such quality remains the risk of postcolonoscopy CRC. However, both incidence and mortality of postcolonoscopy CRC have been strictly associated with ADR. ${ }^{13} 44$
We did not systematically collect the colonoscopy withdrawal time or certain technical aspects of colonoscopy, such as rectal retroflexion, the use of antispasmodic drugs or the dose of sedatives. However, there is no specific policy in Italian programmes - as well as in the European guidelines on the Quality of CRC screening ${ }^{45}$ - to collect these data. Incomplete data on some variables may reflect selection bias from the most dedicated endoscopists.

We did not prospectively test whether interventions targeted at improving the identified predictors would result in an increased ADR. However, simple organisational interventions have already been shown to result in significant improvement in the quality of colonoscopy. ${ }^{46}$

We included in our analysis only the first colonoscopy after a positive FIT, thereby excluding the subsequent procedures scheduled to remove polyps that were judged not to be immediately treatable. This may have caused an underestimation of ADR and possibly an imbalance between endoscopists with different levels of operative skills. However, the detection of adenomas at colonoscopies following negative exams was very low, accounting for a $0.3 \%$ increase of the ADR overall, without any significant differences according to endoscopist characteristics (data not shown).

Finally, our database did not provide accurate information to assess predictors of colonoscopy-related adverse events, due to the lack of a reporting policy for these events within organised screening programme.

In conclusion, our study showed an adequate average level of colonoscopy quality within a nationwide organised FIT screening programme. The observed variability among endoscopists was affected by patient-related, endoscopist-related and centre-related characteristics. Policies addressing the bowel cleansing regimens, retraining for non-GI endoscopists, availability of dedicated screening sessions and moderate use of sedation should improve the quality of colonoscopy in this setting.

\section{Author affiliations}

${ }^{1}$ Registro Tumori del Veneto, Padova, Italy

${ }^{2} \mathrm{CPO}$ Piemonte and San Giovanni Battista University Hospital, Turin, Turin, Italy

${ }^{3}$ Settore promozione e sviluppo igiene e sanità pubblica, Regione Veneto, Venice, Italy

${ }^{4}$ Regione Lazio, Rome, Italy

${ }^{5}$ SS Prevenzione Secondaria e Screening, IRCCS AOU San Martino-IST, Genova, Italy

${ }^{6}$ Department of Oncological Gastroenterology, National Cancer Institute, IRCCS,

Centro di Riferimento Oncologico, Aviano, Italy

${ }^{7}$ U.O. multizonale di Gastroenterologia, Ospedale S. Chiara, Trento, Italy

${ }^{8}$ Agenzia Regionale Sanitaria, Regione Marche, Ancona, Italy

${ }^{9}$ Endoscopia Digestiva, Università di Roma "Sapienza", Azienda Ospedaliera

Sant'Andrea, Rome, Italy

${ }^{10}$ Department of Clinical Epidemiology, Cancer Prevention and Research Institute (ISPO), Florence, Italy

${ }^{11}$ Assessorato alle politiche per la salute, Regione Emilia-Romagna, Bologna, Italy

${ }^{12}$ Unit of Gastroenterology and Digestive Endoscopy, Arcispedale Santa Maria Nuova -IRCCS, Reggio Emilia, Italy

${ }^{13}$ Indiana University School of Medicine, Indiana University Hospital, Indianapolis, Indiana, USA

${ }^{14}$ Gastroenterology Unit, Nuovo Regina Margherita Hospital, Rome, Italy, Rome, Italy

${ }^{15}$ SS Valutazione Screening, Istituto per lo Studio e la Prevenzione Oncologica, Florence, Italy

Correction notice Authors affiliation have been corrected since published Online First.

Collaborators The Equipe Working Group consists of Giuseppe Feliciangeli (ASUR Marche AV3, Macerata, Italy); Cinzia Campari (Azienda unità sanitaria locale, Reggio Emilia, Italy); Fabio Falcini (Unità Operativa di Prevenzione Oncologica, Ospedale Civile GB Morgagni L Pierantoni, AUSL di Forlì, Italy) Orietta Giuliani (Unità Operativa di Prevenzione Oncologica, Ospedale Civile GB Morgagni L Pierantoni, AUSL di Forli, Italy) Omero Triossi (AUSL Ravenna, Italy) Vincenzo Matarese (Unit of Gastroenterology, Departments of General Surgery, S Anna University Hospital of Ferrara, Italy) Chiara Fedato (Veneto Tumour Registry, Padua, Italy) Susanna Baracco (Veneto Tumour Registry, Padua, Italy) Fabio Monica (Gastroenterology Unit, 
S Bassiano Hospital, Bassano del Grappa (VI), Italy Carmen Beatriz Visioli (Clinical and Descriptive Epidemiology Unit, ISPO-Istituto per lo Studio e la Prevenzione Oncologica, Florence, Italy) Francesco Quadrino (Agency for Public Health, Lazio Region, Rome, Italy Ivana Valle (SSD Popolazione a rischio-Dipartimento di Prevenzione, ASL3-Genovese, Genova, Italy) Patrizia Landi (Gastroenterology Unit, PO Bellaria AUSL Bologna, Italy) Elisabetta Buscarini (Gastroenterology Unit, Maggiore Hospital, Crema, Italy) Giovanni de Pretis (Gastroenterology Unit, Ospedale S Chiara, Trento, Italy) Pietro Occhipinti (Gastroenterology Unit, AOU Maggiore della Carità, Novara, Italy) Arrigo Arrigoni (Gastroenterology Unit, AOU Città della Salute e della Scienza, Torino, Italy) Mario Grassini (Gastroenterology Unit, Ospedale Cardinal Massaia, Asti, Italy).

Contributors MZo, CS, CH, MZa: study concept and design; acquisition of data; drafting of the manuscript. MZo, FDR: analysis and interpretation of data; statistical analysis. All the authors: critical revision of the article for important intellectual content and final approval of the article.

Competing interests DR: Olympus—-research support.

Funding The project was financed by the Italian Ministry of Health - CCM (Centre for Disease Control).

Provenance and peer review Not commissioned; externally peer reviewed.

\section{REFERENCES}

1 Edwards BK, Ward E, Kohler BA, et al. Annual report to the nation on the status of cancer, 1975-2006, featuring colorectal cancer trends and impact of interventions (risk factors, screening, and treatment) to reduce future rates. Cancer 2010;116:544-73.

2 Ferlay J, Autier $\mathrm{P}$, Boniol $\mathrm{M}$, et al. Estimates of the cancer incidence and mortality in Europe in 2006. Ann Oncol 2007;18:581-92.

3 Towler BP, Irwig L, Glasziou P, et al. Screening for colorectal cancer using the faecal occult blood test, hemoccult. Cochrane Database Syst Rev 2000:CD001216.

4 Hewitson P, Glasziou P, Watson E, et al. Cochrane systematic review of colorectal cancer screening using the fecal occult blood test (hemoccult): an update. Am J Gastroenterol 2008;103:1541-9.

5 Hol L, Wilschut JA, van Ballegooijen M, et al. Screening for colorectal cancer: random comparison of guaiac and immunochemical faecal occult blood testing at different cut-off levels. Br J Cancer 2009;100:1103-10.

6 Hassan C, Rossi PG, Camilloni L, et al. Meta-analysis: adherence to colorectal cancer screening and the detection rate for advanced neoplasia, according to the type of screening test. Aliment Pharmacol Ther 2012;36:929-40.

7 Zorzi M, Fedato C, Grazzini G, et al. [Screening for colorectal cancer in Italy, 2010 survey]. Epidemiol Prev 2012;36:55-77.

8 Stegeman I, de Wijkerslooth TR, Mallant-Hent RC, et al. Implementation of population screening for colorectal cancer by repeated Fecal Immunochemical Test (FIT): third round. BMC Gastroenterol 2012;12:73.

9 Singh H, Nugent Z, Demers AA, et al. Rate and predictors of early/missed colorectal cancers after colonoscopy in Manitoba: a population-based study. Am J Gastroenterol 2010;105:2588-96.

10 Singh $\mathrm{H}$, Nugent $\mathrm{Z}$, Demers AA, et al. The reduction in colorectal cancer mortality after colonoscopy varies by site of the cancer. Gastroenterology 2010;139:1128-37.

11 Singh $H$, Turner D, Xue L, et al. Risk of developing colorectal cancer following a negative colonoscopy examination: evidence for a 10-year interval between colonoscopies. JAMA 2006;295:2366-73.

12 Baxter NN, Sutradhar R, Forbes SS, et al. Analysis of administrative data finds endoscopist quality measures associated with postcolonoscopy colorectal cancer. Gastroenterology 2011;140:65-72.

13 Kaminski MF, Regula J, Kraszewska E, et al. Quality indicators for colonoscopy and the risk of interval cancer. N Engl J Med 2010;362:1795-803.

14 Rogal SS, Pinsky PF, Schoen RE. Relationship between detection of adenomas by flexible sigmoidoscopy and interval distal colorectal cancer. Clin Gastroenterol Hepatol 2013;11:73-8.

15 Brenner $\mathrm{H}$, Chang-Claude J, Seiler CM, et al. Interval cancers after negative colonoscopy: population-based case-control study. Gut 2012;61:1576-82.

16 Segnan N, Senore C, Andreoni B, et al. Comparing attendance and detection rate of colonoscopy with sigmoidoscopy and FIT for colorectal cancer screening. Gastroenterology 2007;132:2304-12.

17 Lee TJ, Rutter MD, Blanks RG, et al. Colonoscopy quality measures: experience from the NHS Bowel Cancer Screening Programme. Gut 2012;61:1050-7.

18 Bryk AS, Raudenbush SW. Hierarchical Linear Models. Newbury Park, California: Sage 1992.

19 Goldstein H, Rasbash J, Yang M, et al. A multilevel analysis of school examination results. Oxford Review of Education 1993;19:425-33.

20 I numeri del cancro in Italia 2011. Brescia, Italy: Intermedia Editore 2011:37-42. www.registri-tumori.it/cms/node/2172 (accessed 15 May 2014)
21 Denters MJ, Deutekom M, Bossuyt PM, et al. Lower risk of advanced neoplasia among patients with a previous negative result from a fecal test for colorectal cancer. Gastroenterology 2012;142:497-504.

22 Crotta S, Segnan N, Paganin S, et al. High rate of advanced adenoma detection in 4 rounds of colorectal cancer screening with the fecal immunochemical test. Clin Gastroenterol Hepatol 2012;10:633-8.

23 Shah HA, Paszat LF, Saskin R, et al. Factors associated with incomplete colonoscopy: a population-based study. Gastroenterology 2007;132:2297-303.

24 Chokshi RV, Hovis CE, Hollander T, et al. Prevalence of missed adenomas in patients with inadequate bowel preparation on screening colonoscopy. Gastrointest Endosc 2012;75:1197-203.

25 Adler A, Wegscheider $\mathrm{K}$, Lieberman D, et al. Factors determining the quality of screening colonoscopy: a prospective study on adenoma detection rates, from 12,134 examinations (Berlin colonoscopy project 3, BECOP-3). Gut 2013;62:236-41.

26 Gurudu SR, Ramirez FC, Harrison ME, et al. Increased adenoma detection rate with system-wide implementation of a split-dose preparation for colonoscopy. Gastrointest Endosc 2012;76:p603-8 e1.

27 Jover R, Zapater P, Polania E, et al. Modifiable endoscopic factors that influence the adenoma detection rate in colorectal cancer screening colonoscopies. Gastrointest Endosc 2013;77:p381-9 e1.

28 Gavin DR, Valori RM, Anderson JT, et al. The national colonoscopy audit: a nationwide assessment of the quality and safety of colonoscopy in the UK. Gut 2013;62:242-9.

29 Radaelli F, Meucci G, Sgroi G, et al. Technical performance of colonoscopy: the key role of sedation/analgesia and other quality indicators. Am J Gastroenterol 2008; 103:1122-30.

30 Ricci E, Hassan C, Petruzziello L, et al. Inter-centre variability of the adenoma detection rate: A prospective, multicentre study. Dig Liver Dis 2013; 45:1022-7

31 Bretagne JF, Hamonic S, Piette $C$, et al. Variations between endoscopists in rates of detection of colorectal neoplasia and their impact on a regional screening program based on colonoscopy after fecal occult blood testing. Gastrointest Endosc 2010;71:335-41.

32 Rex DK, Bond JH, Winawer S, et al. Quality in the technical performance of colonoscopy and the continuous quality improvement process for colonoscopy: recommendations of the U.S. Multi-Society Task Force on Colorectal Cancer. Am J Gastroenterol 2002;97:1296-308.

33 Cooper GS, Xu F, Barnholtz Sloan JS, et al. Prevalence and predictors of interval colorectal cancers in medicare beneficiaries. Cancer 2012;118:3044-52.

34 Rex DK, Rahmani EY, Haseman JH, et al. Relative sensitivity of colonoscopy and barium enema for detection of colorectal cancer in clinical practice. Gastroenterology 1997;112:17-23.

35 Rabeneck L, Paszat LF, Saskin R. Endoscopist specialty is associated with incident colorectal cancer after a negative colonoscopy. Clin Gastroenterol Hepatol 2010;8:275-9.

36 Hassan C, Rex DK, Zullo A, et al. Loss of efficacy and cost-effectiveness when screening colonoscopy is performed by nongastroenterologists. Cancer 2012;118:4404-11.

37 Leyden JE, Doherty GA, Hanley A, et al. Quality of colonoscopy performance among gastroenterology and surgical trainees: a need for common training standards for all trainees? Endoscopy 2011:43:935-40.

38 Rex DK. Does the use of sedation, or the level of sedation, affect detection during colonoscopy? Am J Gastroenterol 2012;107:1849-51.

39 Bannert C, Reinhart K, Dunkler D, et al. Sedation in screening colonoscopy: impact on quality indicators and complications. The American journal of gastroenterology 2012; 107:1837-48.

40 Wang A, Hoda KM, Holub JL, et al. Does level of sedation impact detection of advanced neoplasia? Digest Dis Sci 2010;55:2337-43.

41 Paspatis GA, Tribonias G, Manolaraki MM, et al. Deep sedation compared with moderate sedation in polyp detection during colonoscopy: a randomized controlled trial. Colorectal Dis 2011;13:e137-44.

42 Lee TJ, Rees CJ, Blanks RG, et al. Colonoscopic factors associated with adenoma detection in a national colorectal cancer screening program. Endoscopy 2014;46:203-11.

43 Murray M, Swan AV, Kiryluk S, et al. The Hawthorne effect in the measurement of adolescent smoking. Journal of epidemiology and community health 1988; 42:304-6.

44 Corley DA, Jensen CD, Marks AR, et al. Adenoma detection rate and risk of colorectal cancer and death. N Engl J Med 2014;370:1298-306.

45 von Karsa L, Patnick J, Segnan N, et al. European guidelines for quality assurance in colorectal cancer screening and diagnosis: overview and introduction to the full supplement publication. Endoscopy 2013;45:51-9.

46 Coe SG, Crook JE, Diehl NN, et al. An endoscopic quality improvement program improves detection of colorectal adenomas. Am J Gastroenterol 2013;108:219-26. 